\title{
EL (IM) POSIBLE APRENDIZAJE DE LA CONCIENCIA HISTÓRICA
}

\author{
THE (IM) POSSIBLE LEARNING \\ OF HISTORICAL AWARENESS
}

\author{
Pablo Aravena Núñez*
}

"La ignorancia del pasado no se limita a impedir el conocimiento del presente, sino que compromete, en el presente, la misma acción".

Marc Bloch, Apología para la historia o el oficio del historiador.

Las investigaciones acerca de enseñanza de la historia aún no son admitidas con propiedad dentro de la disciplina historiográfica, usualmente se las encuentra del lado de la pedagogía, psicología o las llamadas ciencias de la educación. Dicha resistencia la mayor parte de las veces está asociada a la constatación -que universalizada funciona como prejuicio- de que lo que se enseña en las escuelas no tiene que ver demasiado con el saber producido por la institución historiadora.

Cuando la "enseñanza de la historia" es usada deliberadamente como un medio de propaganda de tal o cual régimen sin duda que se aleja de la vocación crítica de la auténtica historiografía, pero cuando existen las garantías políticas, las favorables condiciones de trabajo de los docentes y su compromiso con la labor que ejercen, la enseñanza de la historia potencia las inteligencias de quien la estudia y se liga directamente a los problemas más candentes del quehacer teórico del historiador (que son relevantes justamente por estar ligadas a algún aspecto de la vida práctica del presente). Bastaría una rápida mirada a los textos que reúne el presente número de Diálogo Andino para darse cuenta que los problemas asociados a la enseñanza de la historia tienen directa relación con problemáticas en torno a las posibilidades de aprehensión social de lo que Michel de Certeau denominó "la operación historiográfica", es decir, a las dificultades y resistencias con que se debe enfrentar el saber historiador para realmente hacer sentido y producir una ampliación de las posibilidades de lectura de la realidad en unos sujetos no relacionados directamente con la institución historiadora.
Los atributos de esa operación, más allá del propio De Certeau, han sido señalados por numerosos historiadores y teóricos de la historia -de los que acá recordaremos luego solo lo fundamental-. Pero también parece haber llegado el momento, hoy, de preguntarse si esa operación, si ese modo -finalmente- de representarse la realidad sigue correspondiendo a las circunstancias presentes, es decir, si sirve aún para dar cuenta de unos fenómenos actualísimos y del modo (¿inédito?) en que estos parecen relacionarse.

Ahora, para mayor dificultad, hace tiempo que vivimos una sobreproducción de obras que remiten, o dicen remitir, al pasado. La industria cultural ha encontrado su rasgo definitorio -más o menos desde fines de los setenta, justamente donde comienza la fase postindustrial del capitalismo- apostando por la producción y puesta en circulación de un "pasado-mercancía". Es justamente este fenómeno el que usualmente ha sido señalado como el boom de la historia, el que examinado de cerca tiene que ver justamente con su contrario, es decir, con la devaluación de la operación histórica para hacernos acceder a un pasado sin historia, un pasado que está hecho para ser consumido (gozado) más que para hacer inteligible nuestras condiciones de existencia.

Fredric Jameson ha planteado que pese a "la vuelta del pasado" vivimos una época ahistórica, en la medida que se nos priva de los referentes para proyectar una acción portadora de novedad. La producción cultural (novelas, fotografías, films, etc.) tiende a extraviar los referentes temporales bajo la forma del "simulacro": se escribe, se edita o filma -por ejemplo- como hubiera sido

* Universidad de Valparaíso. Instituto de Historia y Ciencias Sociales. Valparaíso, Chile. 
en los años treinta, se elimina o aísla la huella de la manufactura actual, de modo que esos objetos comienzan a apilarse en un plano horizontal, lo que deviene en una "espacialización" en vez de su lógica (histórica) "temporalización". Se trata de los efectos asociados a nuestra exposición a una producción cultural (desde el arte más abstracto hasta la publicidad) basada en "una nueva cultura de la imagen o el simulacro", trayendo "el consiguiente debilitamiento de la historicidad, tanto en nuestras relaciones con la historia oficial como en las nuevas formas de nuestra temporalidad privada". ${ }^{1}$ Es -según Jameson- una nueva cultura hegemónica: la lógica cultural del capitalismo avanzado.

“... esta nueva e hipnótica moda estética nace como síntoma sofisticado de la liquidación de la historicidad, la pérdida de nuestra posibilidad vital de experimentar la historia de modo activo: no podemos decir que produzca esta extraña ocultación del presente debido a su propio poder formal, sino únicamente para demostrar, a través de sus contradicciones internas, la totalidad de una situación en la que somos cada vez menos capaces de moldear representaciones de nuestra propia experiencia presente". ${ }^{2}$

Se trata entonces de una forma de reproducción del orden económico y del poder mediante esta modalidad de la cultura, pero modificando no específicamente los "contenidos" de esta sino su condición misma (sus a priori): se ha comprimido el tiempo y dilatado el espacio.

Es entonces en la época en que más pasado tenemos a la orden del día, y en donde es posible archivarlo todo, justamente en la que es más difícil la producción de conciencia histórica. Tal como la definiera Raymond Aron en Dimensiones de la conciencia histórica (1961), la conciencia histórica comporta tres elementos específicos: "La conciencia de una dialéctica entre tradición y libertad, el esfuerzo por captar la realidad o la verdad del pasado [y] el sentimiento de que la sucesión de organizaciones sociales y creaciones humanas a través de los tiempos no es cualquiera ni indiferente, que concierne al hombre en lo que este tiene de esencial". ${ }^{3}$

La producción de conciencia histórica no es sencillamente un orientarse en el tiempo, es algo más complejo-que desde luego necesita de la operación historiográfica, pero tal como esta puede servir a quien vive en un presente dilemático. Es ante todo la conciencia de la historicidad de los hombres y mujeres, o su "carácter prometeico": estos no se someten pasivamente al destino, se comprenden condicionados por el pasado, por la tradición, pero no tienen por qué aceptarlo. En este concepto la creencia en la posibilidad de captar la realidad del pasado - cosa en la que ya nadie parece creer, o al menos defender- es fundamental, pues la acción transformadora no llega a ser verosímil si se postula absolutamente arbitraria. Como el mismo Aron lo formulara: "conocer el pasado es una manera de liberarse de él, dado que solo la verdad permite dar asentimiento o repudio con toda lucidez".

¿De qué modo la operación historiográfica sirve a la producción de conciencia histórica? El ya citado De Certeau lo definía en los siguientes términos:

"el pasado es, ante todo, el medio de representar una diferencia. [...] la figura del pasado, conserva su valor primero de representar lo que falta. Con un material que por ser objetivo, está necesariamente ahí, pero es connotativo de un pasado en la medida en que, ante todo, remite a una ausencia, esa figura introduce también la grieta de un futuro. Un grupo, ya se sabe, no puede expresar lo que tiene ante sí -lo que aún falta- más que por una redistribución de su pasado". ${ }^{4}$

Ese material objetivo no es otra cosa que las huellas, los documentos, los "indicios" del pasado a los que se debe el historiador y sin esto su trabajo acaso podría generar los mismos "efectos", pero no fundar la acción con algún grado de pertinencia o "ajuste" al mundo que se quiere intervenir con un fin determinado. Ese efecto aludido es el que se produce al traer el pasado al presente, que es traer siempre una gran dosis de diferencia -incluso en algunos casos intraducible-. Esa diferencia nos interpela de diversas maneras, por ejemplo señalando "lo que falta" -lo perdido, lo sacrificado, lo negado o bien lo traicionado- y nos lanza a lo futuro. Desde luego se puede trabajar de muchos modos con la diferencia, pero el que ha sido propio de la historiografía, y lo que permite la fundación de la conciencia histórica, ha sido el de apostar por la diferencia de un pasado que es posible -aunque sea débil, fragmentaria o precariamente- restituir. Cuando esa diferencia es completamente "fabulada" se puede suscitar 
el "efecto" (de extrañamiento), pero no se puede esperar siquiera que informe a la acción.

Pero en este punto debemos retomar una tentativa que deslizamos al comienzo: ¿Sigue el mundo del presente configurándose bajo las mismas lógicas predominantes del pasado? ¿Nuestro mundo sigue siendo tan histórico como hace cincuenta años? ¿Cómo determinar el grado de continuidad entre pasado y presente para efectos de hacer valer una misma lógica para ambos? ¿Qué parte de la realidad se deja comprender históricamente todavía y cuál no? ¿Vivimos mayormente en un mundo inédito y por ello con escasos referentes para fundar la acción?

Antes de ser descartadas como preguntas insidiosas -que nosotros mismos nos apuraríamos en descartar si vinieran de aquellos mismos sectores que en algún momento proclamaron "el fin de la historia"- debemos de tomarlas en serio y tratar de responder incluso bajo riesgo de que nuestra disciplina se viera finalmente modificada al límite de lo irreconocible. Pues, de otro modo, ¿en qué podríamos fundar eso de que el saber que enseñamos, las operaciones mentales a las que aproximamos a nuestros estudiantes, les sirve para la vida? Quizá sea aún muy temprano para iniciar esta labor crítica acerca de la misma historiografía (temprano tal vez solo porque ni siquiera hemos podido ver demasiados efectos de esta en su versión tradicional moderna), pero el desafío ya ha sido planteado. Al respecto habría que revisar los últimos trabajos de François Hartog, Dipesh Chakrabarty y las audaces propuestas de Sergio Rojas en la versión de una filosofía de la historia situada en Chile. ${ }^{5}$

Por ahora, lo hemos dicho ya, tendremos que hacernos cargo de las formas en que hoy está "puesto en valor" el pasado: la industria cultural, el cine, la televisión, el patrimonio y el turismo. Habrá que ver de qué manera nuestros docentes se dan las herramientas para hacer servir ese pasado a la producción de conciencia histórica.

\section{Notas}

Jameson, Fredric, El posmodernismo o la lógica cultural del capitalismo avanzado, Barcelona: Paidós, 1995, p. 21. Jameson, Fredric, op. cit., p. 52.

Aron, Raymond, Dimensiones de la conciencia histórica, México: Fondo de Cultura Económica, 2004, pp. 103-104.

4 Al respecto ver la formulación del citado Michel de Certeau, "La operación histórica", en: Jacques Le Goff y Pierre
Nora (Comps.), Hacer la historia, Barcelona: Editorial Laia, 1985, p. 53.

5 Ver al respecto François Hartog, Creer en la historia, Santiago: Universidad Finis Terrae, 2015. Dipesh Chakrabarty, Al margen de Europa, Madrid: Tusquets Editores, 2008. Sergio Rojas, El arte agotado, Santiago: Sangría Editora, 2012. 